\title{
Correlation between the High Density Lipoprotein and its Subtypes in Coronary Heart Disease
}

\author{
Fen Gao Ya-juan Ren Xiao-yu Shen Yun-fei Bian Chuan-shi Xiao Hong Li \\ Department of Cardiovascular, the Second Hospital of Shanxi Medical University, Taiyuan, China
}

\section{Key Words}

$\mathrm{HDL}$ subtypes $\cdot \mathrm{CHD} \cdot$ Correlation

\begin{abstract}
Background/Aims: To detect the changes of high density lipoprotein (HDL) and its subtypes in serum of patients with coronary heart disease (CHD). Methods: 337 hospitalized patients were selected from our hospital during August, 2014 - January, 2015, and divided into CHD group $(n=190)$ and control group $(n=127)$. Lipoprint lipoprotein analyzer was used to classify low density lipoprotein (LDL) particle size and its sub-components, as well as HDL particle size and its sub-components. The changes of the subtypes in patients with CHD were statistically analyzed. The possible mechanism was explored. Results: (1) Compared with the control group, the concentration of $\mathrm{HDL}$ in $\mathrm{CHD}$ patients reduced, $\mathrm{HDL}_{\mathrm{L}}$ significantly decreased $(P<0.001)$, while $\mathrm{HDL}_{\mathrm{s}}$ increased $(P<0.001)$; (2) In the patients with HDL less than $1.04 \mathrm{mmol} / \mathrm{L}$ among $C H D$, all $\mathrm{HDL}$ subtypes reduced, but $\mathrm{HDL}_{\mathrm{L}}$ had the most significant decreased; (3) HDL and all HDL subtypes were positively correlated with apolipoprotein A-I (apoA-I), of which, $\mathrm{HDL}_{\mathrm{L}}$ had the biggest correlation with apoA-I $(\mathrm{P}<0.001)$; (4) HDL subtypes had good correlation with $\mathrm{HDL}$, of which, $\mathrm{HDL}_{\mathrm{M}}$ had a maximum correlation with $\mathrm{HDL}(\mathrm{P}<$ 0.001). Conclusion: $\mathrm{HDL}$ maturation disorders existed in the serum of $\mathrm{CHD}$ patients, $\mathrm{HDL}_{\mathrm{L}}$ may be protected factor for CHD, whose decrease was closely related wit the risk increase of CHD. The cardiovascular protection function of $H D L_{L}$ may be related with apoA-I content.
\end{abstract}

(C) 2016 The Author(s)

Published by S. Karger AG, Basel

\section{Introduction}

Coronary atherosclerosis (AS) is an important pathophysiological mechanism in the development of coronary heart disease (CHD). Studies have confirmed that low density lipoprotein (LDL) is an important risk factor for AS.

According to the particle size, LDL can be divided into A and B types. LDL particles with size larger than $265 \AA$ was called big and light LDL, while LDL particles with size smaller than $265 \AA ̊$ was called small density-low density lipoprotein (sd-LDL). Studies have demonstrated that the concentration of sd-LDL was positively correlated with the incidence of CHD [1-3]. 


\section{Cellular Physiology Cell Physiol Biochem 2016;38:1906-1914

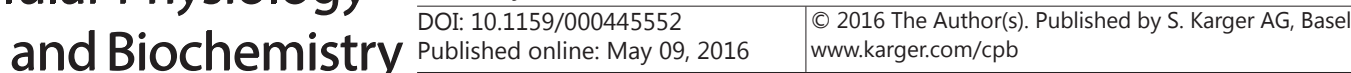 Gao et al.: The Subtypes of HDL and CHD}

A large number of epidemiological studies have demonstrated $[4,5]$ that high density lipoprotein (HDL) levels are negatively correlated with the incidence of CHD. Thus, HDL has long been known as the "anti-atherosclerotic factor" or "cardiovascular protection factor." However, in clinical work, it is found that although the lipidaemia is standard, the HDL levels are normal or even high, significant vascular residual risk still exist [6, 7]. Therefore, HDL of patients with CHD has not only amount problems, but also quality problems. Improving HDL function may be more important than raising its level.

This topic selected CHD patients with standard LDL and negative sd-LDL. According to the particle size, HDL can be divided into 10 subtypes (HDL1-HDL10) using lipoprint HDL lipoprotein analyzer, 1-3 types were large particle types $\left(\mathrm{HDL}_{\mathrm{L}}\right)$, 4-7 types were intermediate particle types $\left(\mathrm{HDL}_{\mathrm{M}}\right)$, and 8-10 types were small particle types $\left(\mathrm{HDL}_{\mathrm{S}}\right)$. The study aimed to investigate the changes of HDL and its various subtypes in the serum of patients with CHD, as well as the possible mechanism.

\section{Materials and Methods}

\section{Study subjects}

Inclusion criteria: In CHD group, the coronary angiography conformed that at least one branch had inner diameter stenosis more than or equal to $50 \%$ in the three main coronary arteries [left anterior descending coronary artery (LAD), left circumflex coronary artery (LCX), right coronary artery (RCA)]. In control group, patients with heart disease were excluded by biochemical indicators, chest radiograph, electrocardiogram, echocardiography, coronary angiography and other tests. Exclusion criteria: diseases affected serum lipoproteins such as pulmonary heart disease, pulmonary hypertension, blood disease, severe liver and kidney dysfunction, severe infection and cancer were excluded. 317 hospitalized cases conformed or excluded by coronary angiography were collected continuously from the Second Hospital of Shanxi Medical University during August, 2014 - January, 2015, and divided into CHD group ( $\mathrm{n}=190,133$ male cases, 57 female cases) and control group ( $\mathrm{n}=127,59$ male cases, 68 female cases). This study was conducted in accordance with the declaration of Helsinki. This study was conducted with approval from the Ethics Committee of the Second Hospital of Shanxi Medical University. Written informed consent was obtained from all participants.

\section{Sampling}

Instructed the subjects to be fasting for $12 \mathrm{~h}$, collected $2 \mathrm{ml}$ venous blood in the next morning for 2 tubes, one was sent to laboratory for measuring general indicators such as serum lipid levels including total cholesterol (TC), triglyceride (TG), low density lipoprotein cholesterol (LDL-C), high density lipoprotein cholesterol (HDL-C), apolipoprotein A (apo-A), apolipoprotein B (apo-B), apolipoprotein E (apo-E), lipoprotein a, blood sugar, liver function, renal function, blood cell analysis, thyroid function; another was performed lipoprotein testing.

\section{LDL subtyps detection}

The total blood analyzed by lipoprotein analyzer was centrifuged with $3000 \mathrm{r} / \mathrm{min}$ for 10 minutes to separate the serum for use. The Lipoprint LDL Gel tubes were placed on racks after drying, $25 \mu \mathrm{l}$ serum samples were added to the tubes, then $200 \mu$ stacking gel, performed upside down for several times to mix with the samples, placed under the irradiation light to irradiate for 30 minutes. Poured $1000 \mathrm{ml}$ electrophoresis buffer at the bottom of the electrophoresis tank, $200 \mathrm{ml}$ buffer in the top of the tank, the gel tube was inserted into the hole, picked bubbles in gel tubes with a needle, set electrophoresis current output, for each gel tube, the maximum output voltage was $500 \mathrm{~V}$ for $3 \mathrm{~mA}$, started electrophoresis. After about 60 minutes, the electrophoresis was finished, the gel tubes were removed, allowed to stand for 30 minutes but no more than 2 hours. During standing, turned on the scanner to warm up, after finishing standing, the gel tubes were placed on the flatbed inside the scanner according to serial numbers, should not spaced, obtained the images after scanning. The scanned images were analyzed using Lipoprint lipoprotein analyzer software to obtain images and data of the distribution for LDL subtypes. 155 CHD patients with LDL particles larger than $265 \AA ̊$ (113 male cases, 42 female cases) and 102 cases ( 44 male cases, 58 female cases) in the control group were selected for the next step detection for HDL subtypes. 


\section{Cellular Physiology Cell Physiol Biochem 2016;38:1906-1914 \begin{tabular}{l|l} 
DOI: 10.1159/000445552 & $\begin{array}{l}\text { O 2016 The Author(s). Published by S. Karger AG, Basel } \\
\text { www.karger.com/cpb }\end{array}$
\end{tabular} Gao et al.: The Subtypes of HDL and CHD}

HDL subtypes detection

Took the Lipoprint HDL Gel tubes, drained the buffer on the upper part of the gel, sucked and dried the buffer inside the wall, and dried the outer surface, the treated gel tubes were placed on tube racks. After drying, the Lipoprint LDL gel tubes were placed on gel racks. The $25 \mu$ l serum samples were added to the gel tube, then $300 \mu \mathrm{l}$ stacking gel, performed upside down for several times to mix with the samples, put under the irradiation lamp for 30 minutes. After irradiation, poured $1000 \mathrm{ml}$ electrophoresis buffer at the bottom of the electrophoresis tank, $200 \mathrm{ml}$ buffer in the top of the tank, the gel tube was inserted into the hole, picked bubbles in gel tubes with a needle, set electrophoresis current output, for each gel tube, the maximum output voltage was $500 \mathrm{~V}$ for $3 \mathrm{~mA}$, started electrophoresis. After about 60 minutes, the electrophoresis was finished, the gel tubes were removed, allowed to stand for 30 minutes but no more than 2 hours. During standing, turned on the scanner to warm up; after finishing standing, the gel tubes were placed on the flatbed inside the scanner according to serial numbers, should not spaced, obtained the images after scanning. The scanned images were analyzed using Lipoprint lipoprotein analyzer software to obtain images and data of the distribution for LDL subtypes.

\section{Statistical analysis}

All data analysis was completed using SPSS17.0 statistical software. The quantitative data consistent with the normal distribution were expressed as mean \pm standard deviation. The comparisons between the two groups were performed using t-test. The data among groups were compared using univariate analysis of variance (ANOVA). The rate comparisons between the two groups were performed using $\chi^{2}$ test. The two factors correlation analysis was performed using bivariate correlation analysis. $\mathrm{P}<0.05$ was considered to be statistically significant.

\section{Results}

\section{General information}

Compared with the control group, the TC, LDL, body mass index (BMI) of the CHD group increased, the proportion of smoking and male increased, while HDL decreased, the difference was statistics significance $(\mathrm{P}<0.05$; Table 1,2$)$.

Concentration comparisons among HDL subtypes

Compared with the control group, HDL and $\mathrm{HDL}_{\mathrm{L}}$ of the CHD group reduced, while HDL and $\mathrm{HDL}_{\mathrm{S}}$ concentration increased (Table 3).

Map results for HDL particles and subtypes between the two groups

Map results for HDL particles and subtypes in the serum of one case in the CHD group and one case in the control group were analyzed and detected by Lipoprint analyzer (Fig. 1, 2).

Table 1. General information comparison between CHD group and control group $(\overline{\mathrm{x}} \pm \mathrm{s})$

\begin{tabular}{lcccc}
\hline Index & CHD group $(\mathrm{n}=155)$ & Control group $(\mathrm{n}=102)$ & T value & P value \\
\hline Age (years old) & $61.52 \pm 9.87$ & $60.03 \pm 9.77$ & -1.192 & 0.235 \\
TC (mmol/L) & $4.78 \pm 1.09$ & $4.15 \pm 1.09$ & 4.103 & $<0.001$ \\
TG (mmol/L) & $1.96 \pm 1.08$ & $1.78 \pm 0.86$ & 0.144 & 0.886 \\
HDL (mmol/L) & $1.08 \pm 0.27$ & $1.22 \pm 0.26$ & 4.293 & $<0.001$ \\
LDL (mmol/L) & $2.81 \pm 1.01$ & $2.35 \pm 0.90$ & 3.657 & $<0.001$ \\
apoA-I (mmol/L) & $1.24 \pm 0.26$ & $1.12 \pm 0.23$ & -2.825 & 0.005 \\
Lp-a (mmol/L) & $186.74 \pm 152.61$ & $140.50 \pm 120.15$ & -1.405 & 0.174 \\
apoE $(\mathrm{mmol} / \mathrm{L})$ & $41.53 \pm 15.95$ & $35.00 \pm 7.24$ & -1.614 & 0.109 \\
\hline
\end{tabular}


Table 2. General information comparison between CHD group and control group

\begin{tabular}{|c|c|c|c|c|c|c|c|}
\hline \multirow{2}{*}{ Index } & \multirow{2}{*}{ Group } & \multicolumn{2}{|c|}{ CHD group $(n=155)$} & \multicolumn{2}{|c|}{ Control group $(n=102)$} & \multirow{2}{*}{$\begin{array}{c}\chi^{2} \\
\text { value }\end{array}$} & \multirow{2}{*}{$P$ value } \\
\hline & & Cases & Rate $(\%)$ & Cases & Rate $(\%)$ & & \\
\hline \multirow{2}{*}{ Sex } & Male & 113 & 72.9 & 44 & 43,1 & \multirow{2}{*}{22.930} & \multirow{2}{*}{$<0.001$} \\
\hline & Female & 42 & 27.1 & 58 & 56.9 & & \\
\hline \multirow{4}{*}{ Age } & $\leq 50$ & 20 & 12.9 & 17 & 16.7 & \multirow{4}{*}{3,581} & \multirow{4}{*}{0.310} \\
\hline & $50 \sim 60$ & 52 & 33.5 & 42 & 41.2 & & \\
\hline & $60 \sim 70$ & 53 & 34.2 & 25 & 24.5 & & \\
\hline & $>70$ & 30 & 19.4 & 18 & 17.6 & & \\
\hline \multirow{4}{*}{ BMI } & Slim & 0 & 0 & 3 & 2.9 & \multirow{4}{*}{12.762} & \multirow{4}{*}{0.005} \\
\hline & Normal & 75 & 48.4 & 35 & 34.3 & & \\
\hline & Overweight & 72 & 46.5 & 50 & 49.0 & & \\
\hline & Obesity & 8 & 5.2 & 14 & 13.7 & & \\
\hline \multirow{2}{*}{ Smoking } & Yes & 84 & 54.8 & 27 & 26.5 & \multirow{2}{*}{20.134} & \multirow{2}{*}{$<0.001$} \\
\hline & No & 70 & 45.2 & 75 & 73.5 & & \\
\hline
\end{tabular}

Table 3. HDL comparisons between control and CHD groups (mg/dl)

\begin{tabular}{lcccc}
\hline Index & Control group $(\mathrm{n}=102)$ & CHDgroup $(\mathrm{n}=155)$ & T value & P value \\
\hline Large & $22.65 \pm 8.38$ & $10.86 \pm 4.48$ & 13.037 & $<0.001$ \\
Intermediate & $18.50 \pm 5.04$ & $20.17 \pm 5.73$ & 2.393 & 0.017 \\
Small & $6.17 \pm 3.36$ & $10.23 \pm 4.03$ & 8.434 & $<0.001$ \\
Total & $47.30 \pm 10.02$ & $41.28 \pm 10.42$ & 4.600 & $<0.001$ \\
\hline
\end{tabular}

Changes of HDL subtypes in patients with $H D L$ decrease in CHD group

Comparisons of HDL $<1.04 \mathrm{mmol} / \mathrm{L}(40 \mathrm{mg} / \mathrm{dl})$ and HDL subtypes in CHD group: various HDL subtypes decreased, but $\mathrm{HDL}_{\mathrm{L}}$ reduced even more significantly (Table $4,5)$.

Correlation between HDL subtypes and apoA-I

Large HDL, intermediate HDL, small HDL and total HDL had good correlation with apoA-I, of which, the large HDL had a correlation maximum with apoA-I (Table 6).

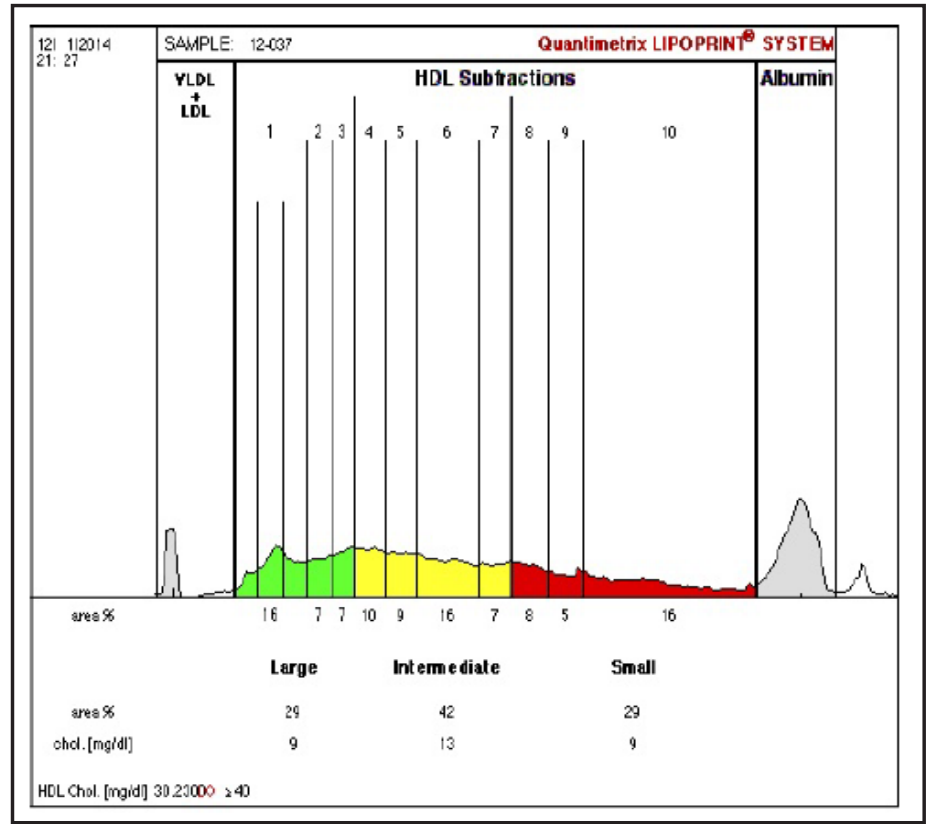

Fig. 1. HDL particle subtype map analysis in CHD group.

Correlation between HDL and HDL subtypes

The correlation analysis between HDL and HDL subtypes showed that all subtypes had obvious relevance with HDL, but correlation between $\mathrm{HDL}_{\mathrm{M}}(\mathrm{r}=0.911, \mathrm{P}<0.001)$ and HDL was larger than that between $\mathrm{HDL}_{\mathrm{M}}(\mathrm{r}=0.695, \mathrm{P}<0.001)$ and $\mathrm{HDL}_{\mathrm{S}}(\mathrm{r}=0.516, \mathrm{P}<0.001$; Table 7; Fig. 3-5). 
Fig. 2. HDL particle subtype map analysis in control group. Note: HDL was divided into 10 sub-components, 1-3 were $\mathrm{HDL}_{\mathrm{L}}$, 4-7 were $\mathrm{HDL}_{\mathrm{M}}$, 8-10 were $\mathrm{HDL}_{\mathrm{S}}$. The HDL $\mathrm{H}_{\mathrm{L}}$ in CHD group was significantly lower, while $\mathrm{HDL}_{\mathrm{L}} \mathrm{HDL}_{\mathrm{M}}$ and $\mathrm{HDL}_{\mathrm{S}}$ significantly increased.

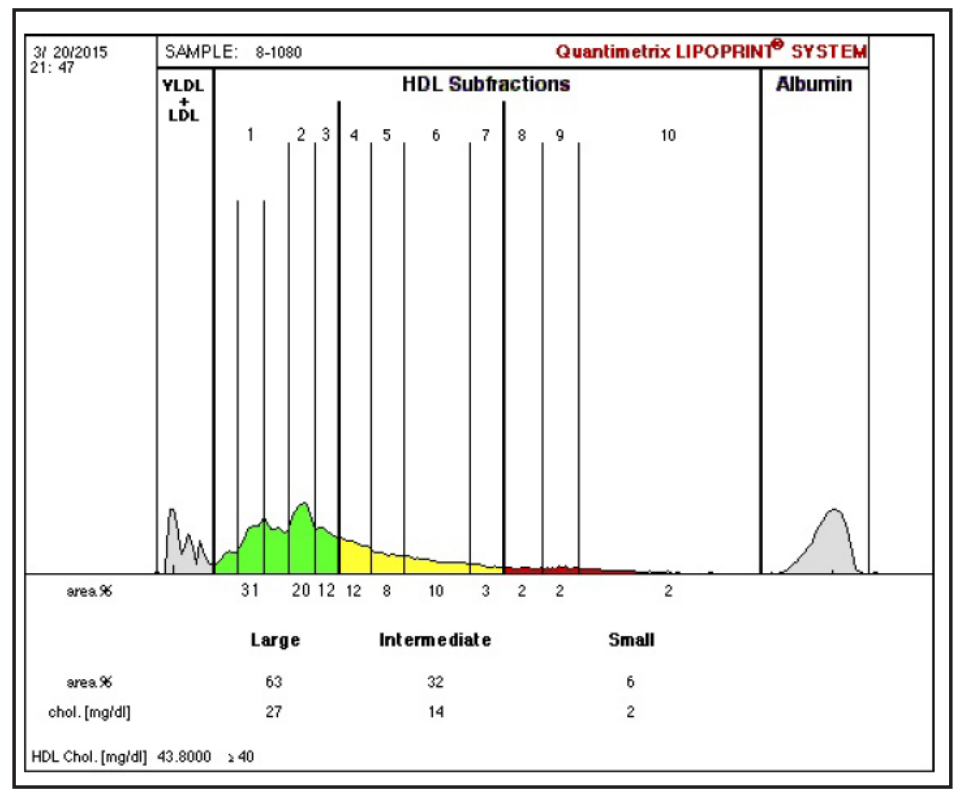

Table 4. HDL subtype comparison between CHD group and HDL $<1.04 \mathrm{mmol} / \mathrm{L}$

\begin{tabular}{lcccc}
\hline Index & CHD group(n=98) & CHD di group(n=57) & T value & P value \\
\hline Large HDL & $10.86 \pm 4.48$ & $8.21 \pm 2.56$ & 5.620 & $<0.001$ \\
Intermediate HDL & $20.17 \pm 5.73$ & $16.13 \pm 3.43$ & 6.581 & $<0.001$ \\
Small HDL & $10.23 \pm 4.03$ & $8.28 \pm 3.26$ & 3.858 & $<0.001$ \\
Total HDL & $41.28 \pm 10.42$ & $32.63 \pm 5.23$ & 8.310 & $<0.001$ \\
\hline
\end{tabular}

Table 5. Reduced rate comparisons among subtypes in HDL reduced group

\begin{tabular}{lcccc}
\hline Index & CHD group(n=98) & CHD di group(n=57) & Reduced rate & P value \\
\hline Large HDL & $10.86 \pm 4.48$ & $8.21 \pm 2.56$ & $24.5 \%$ & $<0.001$ \\
Intermediate HDL & $20.17 \pm 5.73$ & $16.13 \pm 3.43$ & $20 \%$ & $<0.001$ \\
Small HDL & $10.23 \pm 4.03$ & $8.28 \pm 3.26$ & $19.1 \%$ & $<0.001$ \\
Total HDL & $41.28 \pm 10.42$ & $32.63 \pm 5.23$ & $20.1 \%$ & $<0.001$ \\
\hline
\end{tabular}

Table 6. Correlation analysis of different HDL subtypes of CHD and apoA

\begin{tabular}{lcc}
\hline Index & Correlation coefficient $(r)$ & P value \\
\hline apoA*Large HDL & 0.725 & $<0.001$ \\
apoA*Intermediate HDL & 0.432 & $<0.001$ \\
apoA*small HDL & 0.544 & $<0.001$ \\
apoA*Total HDL & 0.642 & $<0.001$ \\
\hline
\end{tabular}

Table 7. Correlation analysis between total HDL and subtype concentration in CHD group (mg/dl)

\begin{tabular}{lcc}
\hline Index & Correlation coefficient $(\mathrm{r})$ & P value \\
\hline Total HDL*Large HDL & 0.695 & $<0.001$ \\
Total HDL*Intermediate HDL & 0.911 & $<0.001$ \\
Total HDL*small HDL & 0.516 & $<0.001$ \\
\hline
\end{tabular}




\section{Discussion}

Coronary AS was an important pathophysiological mechanism of CHD development. The oxidized aggregation of LDL lead to the occurrence of AS, and its subtypes were small and dense. sd-LDL was closely related with CHD [8-10].

According to the particle size, LDL can be divided into two types, LDL with particles larger than $265 \AA$ was called big and light LDL ( LDL $_{\mathrm{L}}$ ), while LDL with particles smaller than $265 \AA$ was called small and dense LDL (sd-LDL). Studies have demonstrated [11] that the sd-LDL concentrations were positively correlated with the incidence of CHD. After collecting clinical specimens, this study firstly detected LDL subtypes by Lipoprint lipoprotein analyzer, then selected LDL specimens with particles larger than $265 \AA$ for further HDL subtype testing, this step avoided the influence of sd-LDL to the experimental results.

Because of its anti-atherosclerotic effect such as reverse cholesterol transport (RCT), anti-oxidation, stablizing already formed plaques, inhibiting the formed plaque rupture, HDL had extensively studied [4, 5, 12]. Large number of epidemiological studies had confirmed that HDL-C levels were negatively correlated with the incidence of CHD. Prospective cardiovascular munster (PROCAM) [13] study found that the incidence of CHD for patients with HDL-C > $0.9 \mathrm{mmol} / \mathrm{L}$ ( $35 \mathrm{mg} / \mathrm{dl}$ ) in the 6-year followup reduced by about $70 \%$ compared with patients with HDL-C less than $0.9 \mathrm{mmol} / \mathrm{L}$ (35 mg/dl). Gordon et al. summarized four large prospective epidemiological studies including US Framingham Heart Study (FHS), lipid research clinics prevalence mortality follow-up study (LRCF), coronary primary prevention trial (CPPT) and multiple risk factor intervention trial (MRFIT) [14], and proposed that the occurrence risk of CHD for male decreased by $2 \%$, cardiovascular disease mortality decreased by $3.7 \%$ when HDL-C increased by $1 \mathrm{mg} / \mathrm{dl}(0.026 \mathrm{mmol} / \mathrm{L})$,

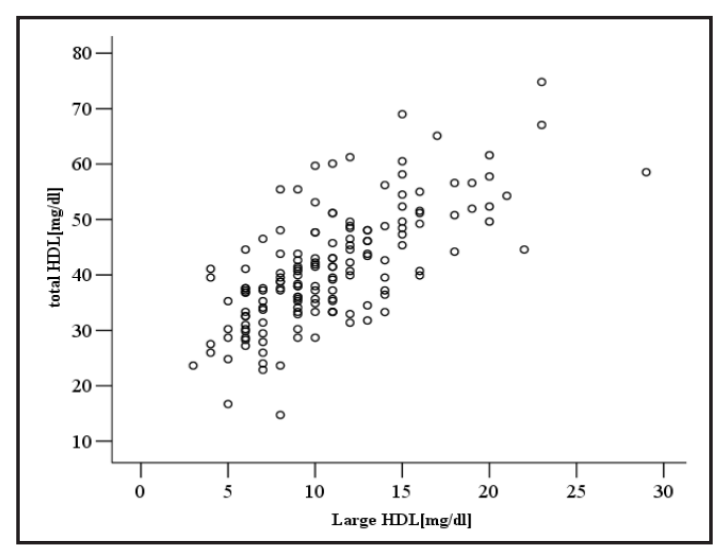

Fig. 3. Correlation scatterplots between $\mathrm{HDL}_{\mathrm{L}}$ and HDL in CHD group.

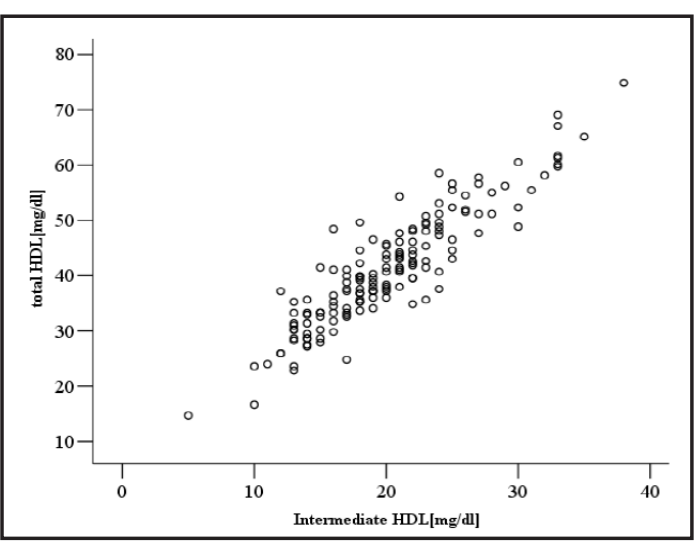

Fig. 4. Correlation scatterplots between $\mathrm{HDL}_{\mathrm{M}}$ and HDL in CHD group.

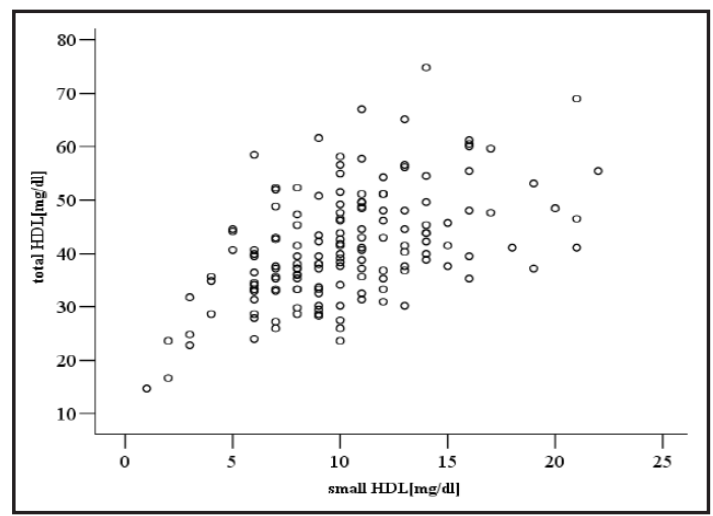

Fig. 5. Correlation scatterplots between $\mathrm{HDL}_{\mathrm{s}}$ and HDL in CHD group.

while the occurrence risk of CHD for female reduced by $3 \%$, and cardiovascular disease mortality decreased by $4.7 \%$, and both were independent of other risk factors including LDL. "China Adult Dyslipidemia Prevention Guide" recommended that HDL-C less than $1.04 \mathrm{mmol} / \mathrm{L}$ (40 mg/dl) was reduced; greater than or equal to $1.04 \mathrm{mmol} / \mathrm{L} \mathrm{(40} \mathrm{mg/dl)}$ was appropriate level; greater than $1.55 \mathrm{mmol} / \mathrm{L}(60 \mathrm{mg} / \mathrm{dl})$ was desired level. US NCEPATPIII stressed that HDL-C less than $1.04 \mathrm{mmol} / \mathrm{L}(40 \mathrm{mg} / \mathrm{dl})$ was reduced, low HDL-C was 
an important risk factor for CHD; greater than or equal to $1.30 \mathrm{mmol} / \mathrm{L}(50 \mathrm{mg} / \mathrm{dl}$ ) was desired level; HDL-C greater than or equal to $1.55 \mathrm{mmol} / \mathrm{L}(60 \mathrm{mg} / \mathrm{dl})$ had a protective role in the prevention of AS. Thus, HDL has long been known as the "anti-atherosclerotic factor" or "cardiovascular protection factor" [15]. However, HDL's role was constantly refreshed [16], the incidence of CHD for patients with HDL gene defect disease did not increase. The ILLUMINATE, RADIANCE, ILLUSTRATE and other studies about cholesterol ester transfer protein, (CETP) inhibitor torcetrapib have found that the use of the drug torcetrapib allowed HDL-C levels significantly increased, but failed to suppress the occurrence and development of atherosclerotic plaques. HPS2 study in 2014 also suggested that only use of niacin to raise HDL did not play the expected protected role from cardiovascular. Clinical work found that although lipidaemia of patients with CHD was standard, and HDL-C levels were normal or even higher, there was still significant vascular residual risk $[6,17,18]$. Therefore, HDL of patients with CHD was not only had amount problems, but also quality problems. Improving HDL function may be more important than raising its level.

HDL volume was the smallest in all lipoproteins. Compared with other lipoproteins, the protein content was the largest, the major apolipoproteins included apoA-I (70\%), apoA-II (20\%) and a small amount of apoC and apoE, the main phospholipid was liposomes. Studies have shown that apoA-I was closely related with HDL functions, and may be associated with changes of HDL subtypes [13]. HDL synthesis started from liver cells or small intestinal epithelial cells. The adenosine triphosphate binding cassette transporter A1 (ABCA1) located in the basement membrane of the cell transported the phospholipids and cholesterol in the transporter cells apoAI outside the cell and formed pre-mature $\beta$-HDL, which can be taken as other sources of cholesterol receptor to accept cholesterol and other ingredients to form mature HDL. The liver and small intestine secreted apoAI, combined with cholesterol and phospholipids outflowing from the liver mediated by ABCA1. The apolipoprotein by LPL hydrolysis from chylomicrons (CMs) and very low density lipoprotein (VLDL) dissociation also combined with apoAI, formed newborn pre-mature $\beta$-HDL particles. The premature $\beta$-HDL can continuously receive the outflowing cholesterol and phospholipid mediated by ABCA1 in extrahepatic tissues, and formed free cholesterol-rich HDL particles. By the role of plasma cholesterol acyltransferase (LCAT), free cholesterol (FC) esterification transformed cholesterol ester (CE) and into the core part of HDL to form mature $\alpha$-HDL, HDL particles gradually became larger during maturation.

Human serum HDL had heterogeneity in size, shape, composition and surface charge. On the basis of the content of HDL surface charge, human serum HDL can be divided into $\alpha$, pre- $\alpha$, pre- $\beta$ and $\gamma$ migration after agarose gel electrophoresis. Of which, the pre-mature $\beta$-HDL were disc-shaped particles under the electron microscope, which were nascent HDL particles; $\alpha$-migration HDL were spherical particles under the electron microscope, which were mature HDL particles. By ultracentrifugation, chemical precipitation, electrophoresis and chromatographic methods [19-21], according to the particle density, $\alpha$-HDL can be subdivided into two main components including HDL2 (large and sparse HDL, $1.063<\mathrm{d}<1.125$ $\mathrm{g} / \mathrm{ml}$ ) and HDL3 (small and dense HDL, $1.125<\mathrm{d}<1.210 \mathrm{~g} / \mathrm{ml}$ ). The EPIC-Norfolk study [22] found that the average diameter decrease of HDL was related with the risk increases of CHD. Kocaman [23] found that cardiovascular protection function of HDL2 was stronger compared with HDL3, HDL2 decline in patients with was more evident.

This paper divided HDL into 10 subtypes (HDL1-HDL 10) using Lipoprint HDL lipoprotein analyzer, 1-3 types were large particle types ( $\mathrm{HDL}_{\mathrm{L}}$ ), 4-7 types were intermediate particle types $\left(\mathrm{HDL}_{\mathrm{M}}\right), 8-10$ types were small particle types $\left(\mathrm{HDL}_{\mathrm{S}}\right)$. This typing method was different from the traditional HDL2, HDL3 typing methods.

This study found that the $\mathrm{HDL}_{\mathrm{L}}$ levels in patients with CHD decreased, while the $\mathrm{HDL}_{\mathrm{M}}$ and $\mathrm{HDL}_{\mathrm{S}}$ content increased. In addition, The study about CHD patients with HDL $<1.04 \mathrm{mmol} / \mathrm{L}$ found that various subtypes of HDL significantly decreased, and the $\mathrm{HDL}_{\mathrm{L}}$ had the most significant decrease. The above two points suggested that serum HDL particles of CHD patients became smaller, there may be mature obstacles. 


\section{Cellular Physiology Cell Physiol Biochem 2016;38:1906-1914

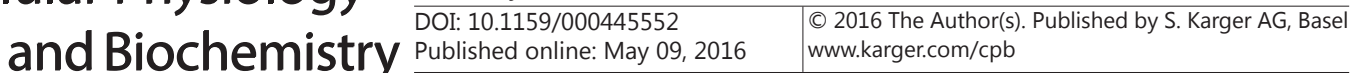 Gao et al.: The Subtypes of HDL and CHD}

The apoAI was the most abundant lipoprotein in HDL. In the correlation analysis about apoAI, it was found that $\mathrm{HDL}_{\mathrm{L}}$ was associated with apoAI at the most compared with $\mathrm{HDL}_{\mathrm{M}}$ and $\mathrm{HDL}_{\mathrm{S}}$, therefore, it was concluded that the cardiovascular protective effects of $\mathrm{HDL}_{\mathrm{L}}$ may be related with apoAI content.

However, the correlation analysis for HDL and HDL subtypes showed that the greatest correlated subtypes with $\mathrm{HDL}$ was $\mathrm{HDL}_{\mathrm{M}}$ not $\mathrm{HDL}_{\mathrm{L}}$, which may be caused due to a larger proportion In HDL.

In summary, the results of this study showed that the simple use of HDL level to predict the risk of CHD was one-sided. The $\mathrm{HDL}_{\mathrm{L}}$ in serum of CHD patients significantly lowered, HDL had maturation disorders. $\mathrm{HDL}_{\mathrm{L}}$ may be a protective factor for CHD, whose decrease was closely related to the risk increase of heart diseases. The cardiovascular protection function of $\mathrm{HDL}_{\mathrm{L}}$ may be related with apoAI content.

\section{Disclosure Statement}

All authors have no conflict of interest regarding this paper.

\section{References}

1 Austin MA, Breslow JL, Hennekens CH, Buring JE, Willett WC, Krauss RM: Low-density lipoprotein subclass patterns and risk of myocardial infarction. JAMA 1988;260:1917-1921.

2 Kwon SW, Yoon SJ, Kang TS, Kwon HM, Kim JH, Rhee J, Lee SJ, Park JK, Lim JY, Yoon YW, Hong BK: Significance of small dense low-density lipoprotein as a risk factor for coronary artery disease and acute coronary syndrome. Yonsei Med J 2006;47:405-414.

3 Baldassarre S, Scruel O, Deckelbaum RJ, Dupont IE, Ducobu J, Carpentier YA: Beneficial effects of atorvastatin on sd LDL and LDL phenotype B in statin-naive patients and patients previously treated with simvastatin or pravastatin. Int J Cardiol 2005;104:338-345.

4 von Eckardstein A, Nofer JR, Assmann G: High density lipoproteins and arteriosclerosis. Role of cholesterol efflux and reverse cholesterol transport. Arterioscler Thromb Vasc Biol 2001;21:13-27.

5 Ansell BJ, Watson KE, Fogelman AM, Navab M, Fonarow GC: High-density lipoprotein function recent advances. J Am Coll Cardiol 2005;46:1792-1798.

6 Hausenloy DJ, Yellon DM: Targeting residual cardiovascular risk: raising high-density lipoprotein cholesterol levels. Postgrad Med J 2008;84:590-598.

7 Cavalcante Lda S, da Silva EL: Application of a modified precipitation method for the measurement of small dense LDL-cholesterol (sd-LDL-C) in a population in southern Brazil. Clin Chem Lab Med 2012;50:16491656.

8 Williams PT, Zhao XQ, Marcovina SM, Brown BG, Krauss RM: Levels of cholesterol in small LDL particles predict atherosclerosis progression and incident CHD in the HDL-Atherosclerosis Treatment Study (HATS). PLoS One 2013;8:e56782.

9 Liu C, Xie G, Huang W, Yang Y, Li P, Tu Z: Elevated serum myeloperoxidase activities are significantly associated with the prevalence of ACS and High LDL-C levels in CHD patients. J Atheroscler Thromb 2012;19:435-443.

10 Zhang B, Miura S, Yanagi D, Noda K, Nishikawa H, Matsunaga A, Shirai K, Iwata A, Yoshinaga K, Adachi H, Imaizumi T, Saku K: Reduction of charge-modified LDL by statin therapy in patients with CHD or CHD risk factors and elevated LDL-C levels: the SPECIAL Study. Atherosclerosis 2008;201:353-359.

11 McKenney J, Ballantyne CM, Feldman TA, Brady WE, Shah A, Davies MJ, Palmisano J, Mitchel YB: LDL-C goal attainment with ezetimibe plus simvastatin coadministration vs atorvastatin or simvastatin monotherapy in patients at high risk of CHD. MedGenMed 2005;7:3.

12 Wang M, Guo H, Wang S, Yang R, Li H, Zhao H, Wang S, Dong J, Chen W: The measurement of high-density lipoprotein mediated cholesterol efflux from macrophage cells by liquid chromatography tandem mass spectrometry. Cell Physiol Biochem 2014;34:1901-1911. 


\section{Cellular Physiology Cell Physiol Biochem 2016;38:1906-1914 \begin{tabular}{c|c} 
DOI: 10.1159/000445552 & $\begin{array}{l}\text { O 2016 The Author(s). Published by S. Karger AG, Basel } \\
\text { www.karger.com/cpb }\end{array}$
\end{tabular} \\ Gao et al.: The Subtypes of HDL and CHD}

13 Assmann G, Schulte H, von Eckardstein A, Huang Y: High-density lipoprotein cholesterol as a predictor of coronary heart disease risk. The PROCAM experience and pathophysiological implications for reverse cholesterol transport. Atherosclerosis 1996;124:S11-20.

14 Gordon DJ, Probstfield JL, Garrison RJ, Neaton JD, Castelli WP, Knoke JD, Jacobs DR, Jr., Bangdiwala S, Tyroler HA: High-density lipoprotein cholesterol and cardiovascular disease. Four prospective American studies. Circulation 1989;79:8-15.

15 Sattler K, Lehmann I, Graler M, Brocker-Preuss M, Erbel R, Heusch G, Levkau B: HDL-bound sphingosine 1-phosphate (S1P) predicts the severity of coronary artery atherosclerosis. Cell Physiol Biochem 2014;34:172-184.

16 Sviridov D, Mukhamedova N, Remaley AT, Chin-Dusting J, Nestel P: Antiatherogenic functionality of high density lipoprotein: how much versus how good. J Atheroscler Thromb 2008;15:52-62.

17 Ridker PM, Genest J, Boekholdt SM, Libby P, Gotto AM, Nordestgaard BG, Mora S, MacFadyen JG, Glynn RJ, Kastelein JJ, Group JTS: HDL cholesterol and residual risk of first cardiovascular events after treatment with potent statin therapy: an analysis from the JUPITER trial. Lancet 2010;376:333-339.

18 Barter P: HDL-C: role as a risk modifier. Atheroscler Suppl 2011;12:267-270.

19 Tian L, Fu M, Jia L, Xu Y, Long S, Tian H, Tian Y: Relationship between apolipoprotein concentrations and HDL subclasses distribution. Lipids 2007;42:419-426.

20 Tian L, Fu M: The relationship between high density lipoprotein subclass profile and apolipoprotein concentrations. J Endocrinol Invest 2011;34:461-472.

21 Phillips MC: New insights into the determination of HDL structure by apolipoproteins: Thematic review series: high density lipoprotein structure, function, and metabolism. J Lipid Res 2013;54:2034-2048.

22 Luben R, Hayat S, Wareham N, Khaw KT: Predicting admissions and time spent in hospital over a decade in a population-based record linkage study: the EPIC-Norfolk cohort. BMJ Open 2016;6:e009461.

23 Kocaman SA, Sahinarslan A, Kunak T, Balcioglu S, Cetin M, Cemri M, Timurkaynak T, Boyaci B, Cengel A: The particular interactions of the traditional cardiovascular risk factors with different circulating specific leukocyte subtype counts in blood: an observational study. Anadolu Kardiyol Derg 2011;11:573-581. 